\title{
Development and characterization of innovative carbon-based waste ashes/epoxy composites
}

\author{
Enrica Stasi ${ }^{\mathrm{a}}$, Antonella Giuri ${ }^{\mathrm{b}}$, Maurizio La Villetta ${ }^{\mathrm{c}}$, Domenico Cirillo ${ }^{\mathrm{c}}$, Gaetano \\ Guerra $^{\mathrm{d}}$, Alfonso Maffezzoli ${ }^{\mathrm{a}}$, Eleonora Ferraris ${ }^{\mathrm{e}}$, Carola Esposito Corcione $^{\mathrm{a}, \mathrm{b}}$ \\ ${ }^{a}$ Dipartimento di Ingegneria dell'Innovazione Università del Salento, 73100 Lecce, Italy; enrica.stasi@unisalento.it;; \\ alfonso.maffezzoli@unisalento.it; carola.corcione@unisalento.it \\ ${ }^{b}$ Istituto di Nanotecnologia CNR-Nanotec, Polo di Nanotecnologia clo Campus Ecotekne, Via Monteroni, 73100 Lecce, Italy; \\ antonella.giuri@unisalento.it \\ ${ }^{c}$ C.M.D. Costruzioni Motori Diesel S.p.A., Via Pacinotti, 2, 81020 San Nicola La Strada (CE), Italy; maurizio.lavilletta@cmdengine.com; \\ domenico.cirillo@cmdengine.com \\ ${ }^{d}$ Dipartimento di Chimica e Biologia, Università di Salerno, 84084 Fisciano (SA), Italy; gguerra@unisa.it \\ e Department of Mechanical Engineering, Campus de Nayer, KU Leuven; eleonora.ferraris@kuleuven.be
}

Corrisponding author: carola.corcione@unisalento.it

\begin{abstract}
In this study, carbon based ashes were produced by the wooden biomass pyro-gasification plant CMD ECO20. CMD ECO20 is a micro-scale combined heat and power system powered with biomass, under development by the Italian company Costruzioni Motori Diesel (C.M.D) S.p.A. It is an integrated system combining a downdraft gasifier, a spark ignition internal combustion engine, an electric generator and syngas cleaning devices, and it is able to produce electric and thermal power up to $20 \mathrm{kWe}$ and $40 \mathrm{kWth}$

Three different types of fillers were produced from ashes starting from innovative green waste: the first type (MA) was obtained by mortar milling, while the second (DBA) and the third (WBA) one were produced by dry and wet ball milling, respectively. MA, DBA e WBA fillers were characterized by several techniques including Scanning Electron Microscopy (SEM), Multi-angle light scattering (MALS) and Energy Dispersive X-ray (EDX) Spectrometry. Each filler was added to epoxy resin EC01 in an amount equal to $1,3,5$ and $10 \mathrm{wt} \%$. The curing agent (22phr) was added to the resin that was cured for $1 \mathrm{~h}$ at $60{ }^{\circ} \mathrm{C}$ and $2 \mathrm{~h}$ at $150{ }^{\circ} \mathrm{C}$. Finally, the flexural properties and the glass transition temperature of the cured neat epoxy and ashes filled epoxy composites were measured.

The elastic modulus of the epoxy resin containing an amount of fillers from 1 to $10 \mathrm{wt} \%$ is higher in comparison to that of the neat epoxy. The flexural strength of the epoxy resin containing an amount of DBA of $3 \mathrm{wt} \%$ is also higher than that of the neat epoxy. [copyright information to be updated in production process]
\end{abstract}

Keywords: carbon based ashes; epoxy composites; flexural properties

\section{Introduction}

CMD ECO 20 is a system designed by Costruzioni Motori Diesel (C.M.D.) SpA for the combined production of electricity and heat by thermo-chemical decomposition or molecular dissociation of green wastes at high temperature (from 600 to $1000{ }^{\circ} \mathrm{C}$ ) in complete absence or minimum quantities of oxygen (pyro-gasification). This emerging technology improves energy efficiency and environment by reducing primary energy consumption and associated greenhouse gas emission, in addition to complying with social aims for increased decentralisation of energy supply in rural area [1, 2]. However, CMD ECO 20 plant produces waste consisting of carbon-based ashes. 
The potential uses of carbon-based ashes mostly include soil amendment and fertilisation methods, followed by production of construction materials and sorbents, and the occasional synthesis and production of minerals, ceramics and other materials [3].

In the present work, an innovative reutilisation of carbon-based ashes is proposed. Specifically, a high quality and cost-efficient approach to reinforce epoxy resins and fabricate low-price high performance composites is explored.

In the last few years, various carbon-based nanofillers have been used to reinforce epoxy resins. The incorporation of graphene nanoplatelets (GnPs), with a thickness of $\sim 5$ to $10 \mathrm{~nm}$, enhanced the flexural modulus of cured epoxy resins with increasing GnPs loading regardless of the particle size [4]. The composite reinforced with $5 \mathrm{wt} \%$ of GnPs with an average diameter of around $5 \mu \mathrm{m}$ and surface area of $150 \mathrm{~m} 2 / \mathrm{g}(\mathrm{GnP}-5)$ showed a $25.7 \%$ increase in flexural modulus, over the neat epoxy, while the modulus of the composite with GnPs characterized by a diameter smaller than $1 \mu \mathrm{m}$ and a surface area of $750 \mathrm{~m} 2 / \mathrm{g}$ (GnP-C750) showed a much lower increase with content of GnP-C750 from 3 to $5 \mathrm{wt} \%$. Unlike the modulus, the strength reinforcement of $\mathrm{GnP}-5$ and $\mathrm{GnP}-\mathrm{C} 750$ behaved differently. The addition of GnPC750 increased the flexural strength from 130 to $142 \mathrm{MPa}(3 \mathrm{wt} \%)$ and $145 \mathrm{MPa}(5 \mathrm{wt} \%)$. However, the incorporation of GnP-5 decreased the strength of the composites [4]. The flexural modulus also enhanced with the increase of graphene sheets loading regardless of the dispersion level. However, the strength of the composites with the poorly dispersed graphene sheets decreased dramatically in comparison to that of the composites with the homogeneously dispersed graphene fillers [5]. Furthermore, expanded graphene stacks (EGS) filled epoxy composites showed a higher elastic modulus and strength than the neat epoxy matrix. The flexural modulus increased, in comparison with that of the neat matrix, of $10 \%$ and $25 \%$ for an EGS content of $1 \mathrm{wt} \%$ and $3 \mathrm{wt} \%$, respectively, while the flexural strength enhanced of $17 \%$ with the addition of $3 \mathrm{wt} \%$ of EGS, when compared to the matrix [6,7]. Thus, carbon nanofillers could improve the mechanical properties of the composites at low loading amount, however the relative high price of these fillers mostly limits the large-scale applications in industry. Activated carbon (AC) was found to be an effective reinforcing nanofiller. After $0.3 \% \mathrm{AC}$ was incorporated in the epoxy matrix, the tensile strength and modulus increased by $19.4 \%$ and $30.7 \%$, respectively. AC is one of the most common and low-price carbon materials. ACs result of carbonization of biomass and, therefore, they are rich of oxygen groups that could induce chemical interactions with the matrix. AC is also hundred times cheaper than graphene [8].

According to the authors there are no previous evidences of such an approach. The original contribution of the present work is given by the use of carbon based waste fillers to reinforce epoxy resins. The carbon fillers were characterized by several techniques including Scanning Electron Microscopy (SEM), Multi-angle light scattering (MALS) and Energy Dispersive X-ray (EDX) Spectrometry; and they were added to the selected epoxy resin in an amount equal to $1,3,5$ and $10 \mathrm{wt} \%$. The neat epoxy and the carbon based ashes filled epoxy were cured, and the flexural properties and the glass transition temperature of both were measured and compared each other. As a result, a high quality and price efficient approach to reinforce epoxy resins could be derived by a simple and eco-friendly processing method.

\section{Materials and methods}

\subsection{Resin and curing agent}

The epoxy resin EC01 was used in this work and it was purchased by Elantas Electrical Insulation.

The curing agent isophorondiamine (IPDA) was supplied by Sigma Aldrich. According to the stoichiometric ratio, 22 parts of hardener (i.e. $22 \mathrm{phr}$ ) were added to 100 parts of the epoxy resin.

\subsection{Ashes}

The ashes were produced by the biomass pyro-gasification plant CMD ECO20, starting from innovative green waste. CMD ECO20 is a micro-scale combined heat and power (mCHP) system powered with biomass, under development by the Italian company Costruzioni Motori Diesel S.p.A. (CMD). The mCHP unit is an integrated system combining a downdraft gasifier, a spark ignition internal combustion engine, an electric generator and syngas cleaning devices. In a downdraft gasifier, biomass and syngas move in the same direction and it includes drying, pyrolysis, combustion and gasification zones.

The CMD ECO 20 is designed to process wooden biomass of G30 size $(1.50$ to $3.00 \mathrm{~cm})$ and max at $20 \%$ of humidity. It is able to produce electric and thermal power up to $20 \mathrm{kWe}$ and $40 \mathrm{kWth}$. The system is a fully automated machine, electronically managed at every stage of operation: from the automatic loading of the biomass into the 
hopper, the start-up and operation of the gasification reactor, the starting of the generator up to the realization of the parallel connection with the electric national grid. The control system manages the ash discharge, the condensed matter, the biochar and thanks to the presence of sensors and automatic safety alarms, it reacts to situations of failures according to given strategies until the system shutdowns. The CMD ECO 20 has a web service interface through which it is possible to: i) analyse the stored data; ii) monitor the device parameters; and iii) manage the system via internet connection, without the presence of the operator within the operative environment [1].

Table 1 lists the main parameters of the biomass pyro-gasification process used in this work.

Table 1. Parameters of biomass pyro-gasification process

\begin{tabular}{ll}
\hline Parameters & Values \\
\hline Drying temperature $\left({ }^{\circ} \mathrm{C}\right)$ & 107.32 \\
Combustion temperature $\left({ }^{\circ} \mathrm{C}\right)$ & 928.06 \\
Reduction temperature $\left({ }^{\circ} \mathrm{C}\right)$ & 799.05 \\
Reduction bed temperature $\left({ }^{\circ} \mathrm{C}\right)$ & 413.97 \\
Drying pressure (mbar) & -10.24 \\
Combustion pressure (mbar) & -3.45 \\
Reduction pressure (mbar) & -42.84 \\
Reduction bed pressure (mbar) & -50.52 \\
\hline
\end{tabular}

Three different types of fillers were produced from ashes: the first type (MA) was obtained by mortar milling, while the second (DBA) and the third (WBA) one were produced by dry and wet ball milling, respectively.

For the preparation of the second type of fillers (DBA), $100 \mathrm{~g}$ of ashes were milled for $24 \mathrm{~h}$ in an aluminous porcelain jar $(1.5 \mathrm{Lt})$ using alumina balls in ambient atmosphere. The mechanical milling was performed in a horizontal oscillatory mill (MMS-Ball Mill) operating at $25 \mathrm{~Hz}$. For the production of the third type of fillers (WBA), $50 \mathrm{~g}$ of dry ground ashes were dispersed in $1 \mathrm{Lt}$ of water, and were milled for other $72 \mathrm{~h}$. They were then dried over night on a hot plate at $60{ }^{\circ} \mathrm{C}$. Table 2 summarizes the name and preparation procedure of the fillers.

Table 2. Name and preparation procedure of fillers

\begin{tabular}{ll}
\hline Name & Preparation procedure \\
\hline MA & Mortar milled Ashes \\
DBA & Dry Ball milled Ashes \\
WBA & Water Ball milled Ashes \\
\hline
\end{tabular}

\subsection{Preparation of epoxy/ashes composites}

Each filler was added to the EC01 epoxy matrix according to the following amounts: 1, 3, 5 and $10 \mathrm{wt} \%$. The filled epoxy mixture was stirred for $5 \mathrm{~h}$ at $80^{\circ} \mathrm{C}$ and $400 \mathrm{rpm}$ and subsequently degassed under vacuum at $\mathrm{T}=60{ }^{\circ} \mathrm{C} .22$ phr of IPDA were finally added to the filled resin mixture and the composite was cured for $1 \mathrm{~h}$ at $60^{\circ} \mathrm{C}$ and $2 \mathrm{~h}$ at 150 ${ }^{\circ} \mathrm{C}$. Table 3 reports the name and composition of the mixtures.

Table 3. Name and composition of mixtures

\begin{tabular}{ll}
\hline Name & Weight Composition \\
\hline Neat epoxy & $82 \%$ of epoxy resin+ $8 \%$ of IPDA \\
Epoxy_MA 1 & $81 \%$ of epoxy resin $+1 \%$ of MA+18\% of IPDA \\
Epoxy_MA 3 & $79.6 \%$ of epoxy resin $+3 \%$ of MA+17.4 of IPDA \\
Epoxy_MA 5 & $78.6 \%$ of epoxy resin $+5 \%$ of MA+16.4 of IPDA \\
Epoxy_MA 10 & $74.6 \%$ of epoxy resin $+10 \%$ of MA $+15.4 \%$ of IPDA \\
Epoxy_DBA 1 & $81 \%$ of epoxy resin $+1 \%$ of DBA $+18 \%$ of IPDA \\
Epoxy_DBA & $79.6 \%$ of epoxy resin $+3 \%$ of DBA +17.4 of IPDA \\
Epoxy_DBA & $78.6 \%$ of epoxy resin $+5 \%$ of DBA +16.4 of IPDA
\end{tabular}




$\begin{array}{ll}\text { Epoxy_DBA }_{10} & 74.6 \% \text { of epoxy resin+10\% of DBA+15.4\% of IPDA } \\ \text { Epoxy_WBA }_{1} & 81 \% \text { of epoxy resin+1\% of WBA+18\% of IPDA } \\ \text { Epoxy_WBA }_{3} & 79.6 \% \text { of epoxy resin+3\% of WBA+17.4 of IPDA } \\ \text { Epoxy_WBA }_{5} & 78.6 \% \text { of epoxy resin+5\% of WBA+16.4 of IPDA } \\ \text { Epoxy_WBA }_{10} & 74.6 \% \text { of epoxy resin+10\% of WBA }+15.4 \% \text { of IPDA }\end{array}$

\subsection{Characterization techniques}

The morphology of the fillers was characterized by scanning electronic microscopy (SEM) using a Zeiss Scanning Electron Microscope Evo40. The size was measured by multi-angle light scattering (MALS) using a CILAS 1190 particles size analyzer.

Organic elemental analysis was performed with a Thermo FlashEA 1112 Series CHNS-O analyzer (Thermo Fisher Scientific, Waltham, MA, USA) after pretreating samples in an oven at $100{ }^{\circ} \mathrm{C}$ for $12 \mathrm{~h}$, by using 2,5-Bis-2 (5-tertbutyl-benzoxalyl) thiophene as standard.

Elemental analysis was carried out on an optical emission spectrometer Optima 7000 DV (Perkin Elmer, Waltham, MA, USA), while energy dispersive X-ray (EDX) analysis of each filler was performed with a Bruker, XFlash detector 5010 .

The rheological characterization of the mixtures was carried out in a strain controlled rheometer (Ares TA Instrument), adopting a parallel plate configuration, with plates $25 \mathrm{~mm}$ in diameter. The viscosity of all formulations was measured at room temperature in steady state mode with a shear rate ranging from 0.5 to $100 \mathrm{~s}-1$. The rheological experiments were repeated at least three times on each sample.

The glass transition temperature of the neat epoxy and composites was measured using a differential scanning calorimetric (DSC; Mettler Toledo 622). The cured samples were heated from 20 to $250{ }^{\circ} \mathrm{C}$ at $10{ }^{\circ} \mathrm{C} / \mathrm{min}$ under nitrogen atmosphere, and at least three tests on each sample were performed.

The flexural properties of each cured sample were measured using a dynamometer, Lloyd LR5K, according to the ASTM D790 (three points bending with specimen dimension: 120 X 10 X $4 \mathrm{~mm}$ ). The span length used for the tests was $75 \mathrm{~mm}$ with relative span/thickness ratio of 18.75 . Five repetitions were performed on each sample.

\section{Experimental results}

\subsection{Characterization of ashes fillers}

Information on the morphology and size of the ashes fillers was obtained by SEM and MALS analysis.

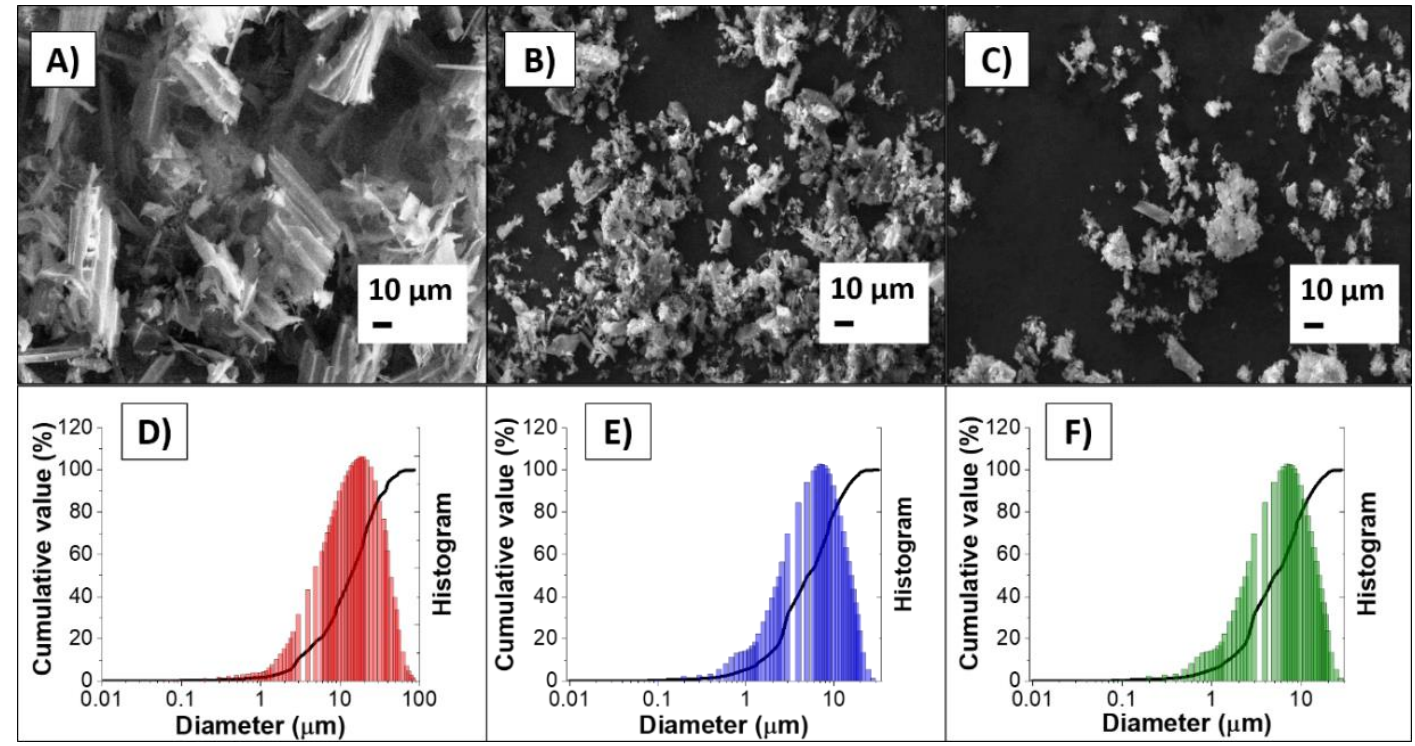

Fig. 1. SEM images of A) MA, B) DBA and C) WBA; MALS measurements of D) MA, E) DBA and F) WBA fillers 
A SEM image of the MA filler (see Figure $1 \mathrm{~A}$ ) shows particles/fragments of ashes about $40 \mu \mathrm{m}$ in size; SEM images of DBA (Figure $1 \mathrm{~B}$ )) and WBA (Figure $1 \mathrm{C})$ ) reveal that after the ball milling the size of the particles/fragments is reduced from 40 to around 20 and $14 \mu \mathrm{m}$, respectively. The MALS analysis confirms that $90 \%$ of the MA (Figure 1 D)), DBA (Figure 1 E)) and WBA (Figure 1 F)) particles has a diameter of $38.86 \mu \mathrm{m}, 20.06 \mu \mathrm{m}$ and $14.37 \mu \mathrm{m}$, respectively.

\begin{tabular}{cccc}
\multicolumn{5}{c}{ Table 4. OEA, ICP-OES and EDX analysis of the ashes fillers } \\
\hline Element & $\%$ (OEA) & $\mathrm{mg} / \mathrm{ml}$ (ICP-OES) & $\%$ (EDX) \\
\hline $\mathrm{C}$ & 75.80 & - & 77.63 \\
$\mathrm{Ca}$ & - & 384.4 & 3.41 \\
$\mathrm{~K}$ & - & 261.1 & 2.34 \\
$\mathrm{O}$ & 22.69 & - & 13.57 \\
\hline
\end{tabular}

The organic elemental analysis (OEA) of the carbon based ashes (Table 4) shows that the percentage of carbon is about $76 \%$ while that of oxygen is about $23 \%$. Nitrogen and hydrogen are present in a percentage $<1 \%$. Similarly, the ICP-OES analysis (Table 4) underlines that the main elements in decreasing order of abundance are $\mathrm{Ca}>\mathrm{K}>\mathrm{Na}>\mathrm{P}$ $>\mathrm{Mg}>\mathrm{Al}>\mathrm{Fe}>\mathrm{Zn}$, while other elements are present in traces. These results are also partially confirmed by EDX spectroscopy. Specifically, the EDX analysis reports (Table 4) that in each sample the most abundant element is carbon, present in a percentage of about $78 \%$. Several atomic elements can also be observed at different concentrations. The most abundant elements, beside carbon, (>1\%) are $\mathrm{O}, \mathrm{Ca}$ and $\mathrm{K}$. The following elements are present in an amount lower than 1\%: $\mathrm{Al}, \mathrm{As}, \mathrm{Cl}, \mathrm{Fe}, \mathrm{Mg}, \mathrm{Na}, \mathrm{P}$ and $\mathrm{S}$.

\subsection{Characterization of liquid ashes - epoxy mixture}

In order to verify whether the presence of ashes in the epoxy liquid resin affects the viscosity and, hence, the processability of an epoxy matrix composite (i.e. resin flow for fiber impregnation and mold filling), a rheological analysis of each formulation was performed as a function of type and amount of filler. 

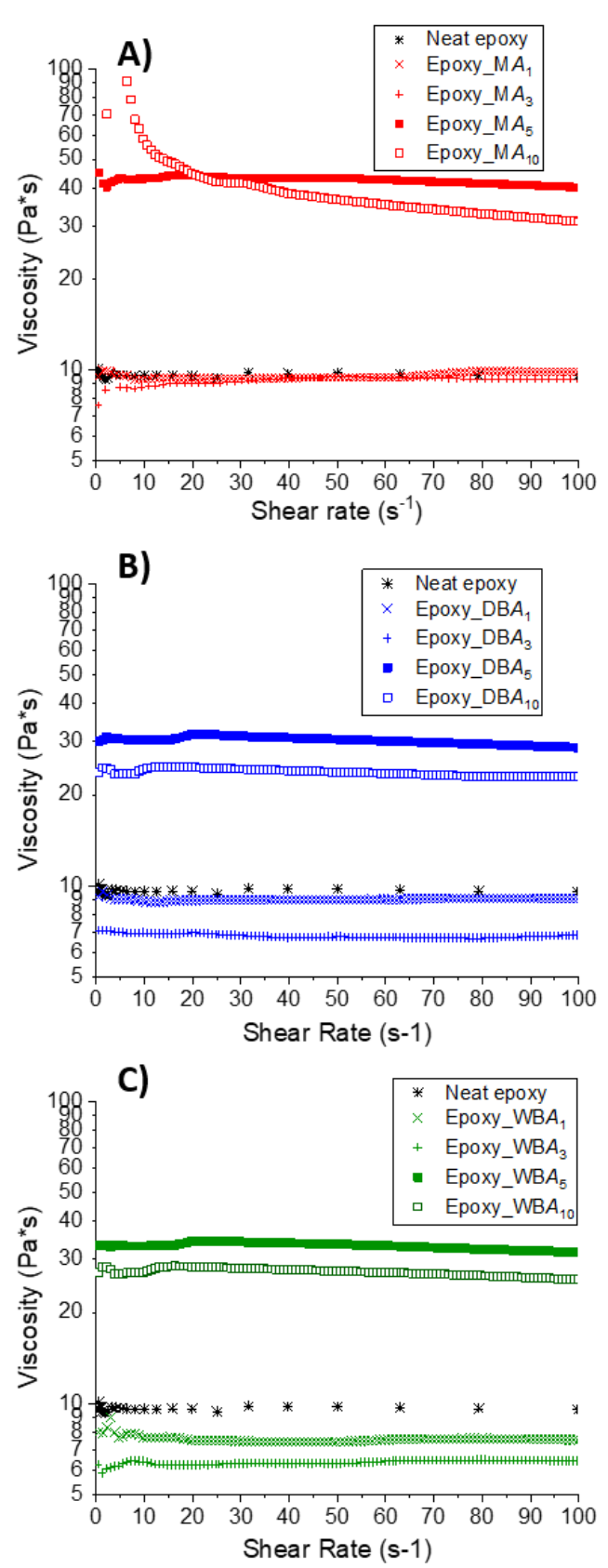

Fig. 2 Rheological behaviour of liquid epoxy mixtures filled with different amounts of ashes fillers

A comparison between the viscosity of the epoxy mixtures containing different amounts of MA, DBA and WBA at $20{ }^{\circ} \mathrm{C}$ is reported in Figure $2 \mathrm{~A}, \mathrm{~B}$ and $\mathrm{C}$, respectively. The viscosity appears almost constant with the shear rate, so all the mixtures show a quasi-Newtonian behavior. Moreover, the viscosity of the epoxy mixtures containing an amount of ashes fillers equal to $1 \mathrm{wt} \%$ and $3 \mathrm{wt} \%$ does not change in comparison to that of the neat epoxy resin, while the viscosity of the epoxy mixture containing an amount of fillers equal to $5 \mathrm{wt} \%$ and $10 \mathrm{wt} \%$ strongly increases, irrespective to the type of filler. A mild pseudo-plastic behavior was observed for the formulation containing $10 \mathrm{wt} \%$ of MA filler, with a clear decreasing behavior of the viscosity as a function of the shear rate. On the other hand, this latter formulation evidences the highest viscosity, also associated to a yield stress at low shear rate, probably due to the larger size of the filler, in comparison to other $10 \mathrm{wt} \%$ loaded samples.

\subsection{Characterization of the cured samples}


The influence of the type and amount of the carbon based ashes on the mechanical properties of composite epoxies against to the neat epoxy cured resin was also evaluated. The results are summarized in Table 5 and reported in Figs. 3,4 and 5 .

\begin{tabular}{cccc}
\multicolumn{4}{c}{ Table 5. Mechanical properties of ashes filled epoxy } \\
\hline Sample & E(GPa) & $\sigma(\mathrm{MPa})$ & $\varepsilon(\%)$ \\
\hline Neat epoxy & $3.10 \pm 0.09$ & $34.10 \pm 2.0$ & $1.11 \pm 0.22$ \\
Epoxy_MA $_{1}$ & $3.34 \pm 0.18$ & $28.89 \pm 0.4$ & $0.86 \pm 0.11$ \\
Epoxy_MA $_{3}$ & $3.95 \pm 0.09$ & $18.94 \pm 0.9$ & $0.47 \pm 0.09$ \\
Epoxy_MA $_{5}$ & $5.16 \pm 0.25$ & $18.19 \pm 0.8$ & $0.35 \pm 0.09$ \\
Epoxy_MA $_{10}$ & $5.77 \pm 0.01$ & $18.59 \pm 0.8$ & $0.32 \pm 0.09$ \\
Epoxy_DBA $_{1}$ & $6.35 \pm 1.80$ & $42.65 \pm 2.2$ & $0.67 \pm 0.10$ \\
Epoxy_DBA $_{3}$ & $4.86 \pm 0.24$ & $48.42 \pm 2.4$ & $0.98 \pm 0.11$ \\
Epoxy_DBA $_{5}$ & $5.40 \pm 0.27$ & $45.72 \pm 2.2$ & $0.85 \pm 0.12$ \\
Epoxy_DBA $_{10}$ & $4.86 \pm 0.5$ & $37.86 \pm 1.8$ & $0.78 \pm 0.12$ \\
Epoxy_WBA $_{1}$ & $4.24 \pm 0.8$ & $33.01 \pm 1.6$ & $0.80 \pm 0.12$ \\
Epoxy_WBA $_{3}$ & $4.19 \pm 0.20$ & $31.85 \pm 1.6$ & $0.74 \pm 0.13$ \\
Epoxy_WBA $_{5}$ & $4.50 \pm 0.3$ & $31.93 \pm 1.5$ & $0.70 \pm 0.10$ \\
Epoxy_WBA $_{10}$ & $6.0 \pm 0.3$ & $33.99 \pm 1.6$ & $0.57 \pm 0.12$ \\
\hline
\end{tabular}

(A)

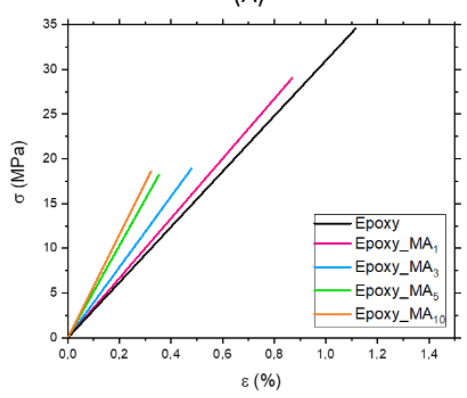

(B)

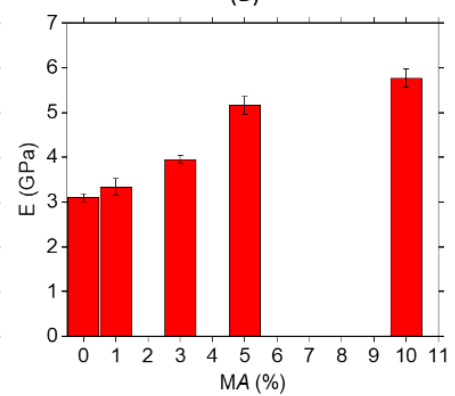

(C)

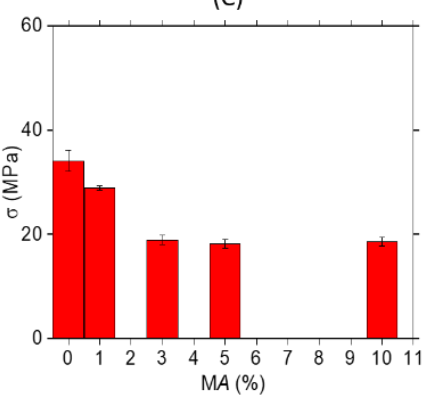

(D)

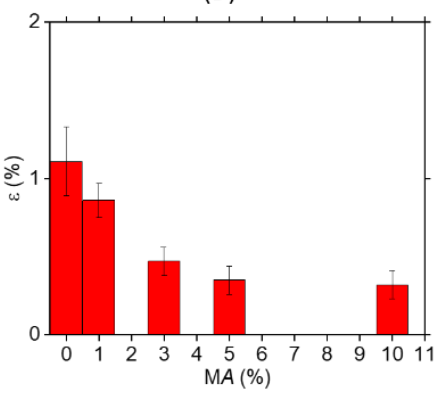

Fig. 3 A) Stress-strain curves of epoxy resin with different amount of MA and B) flexural modulus, C) strength and D) strain of composites as function of the content of MA

(A)

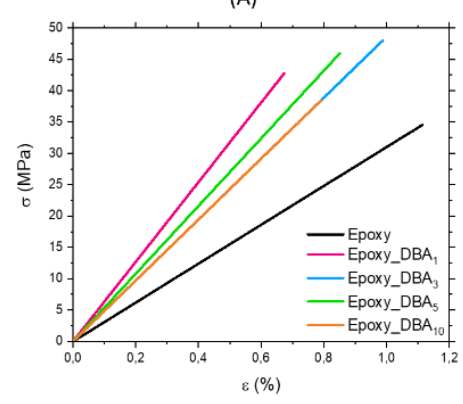

(B)

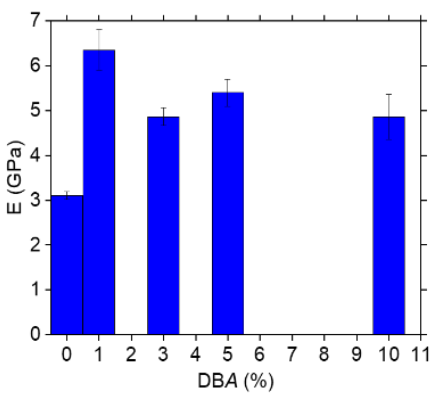

(C)

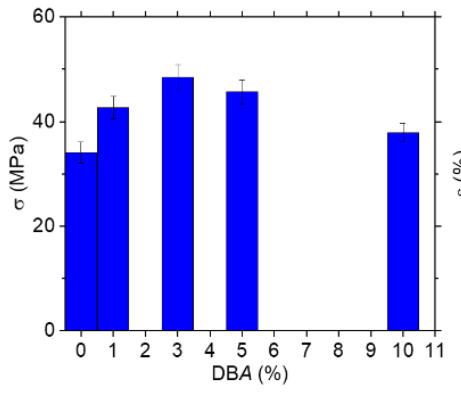

(D)

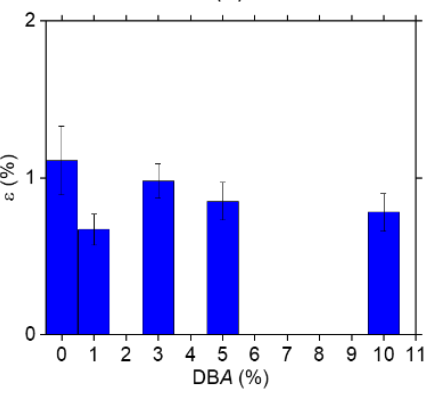

Fig. 4 A) Stress-strain curves of epoxy resin with different amount of DBA and B) flexural modulus, C) strength and D) deformation of composites as function of the content of DBA 
(A)

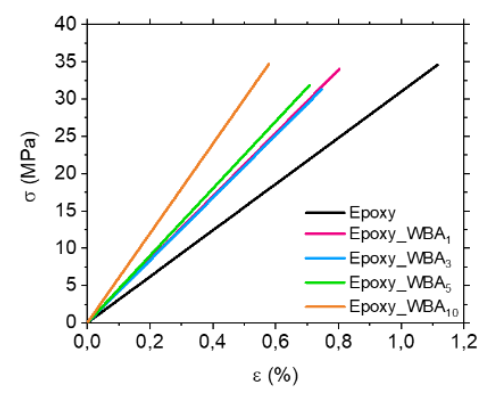

(B)

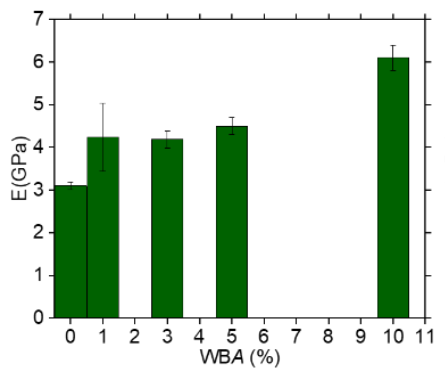

(C)

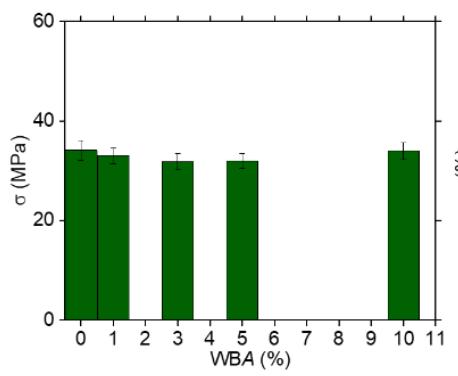

(D)

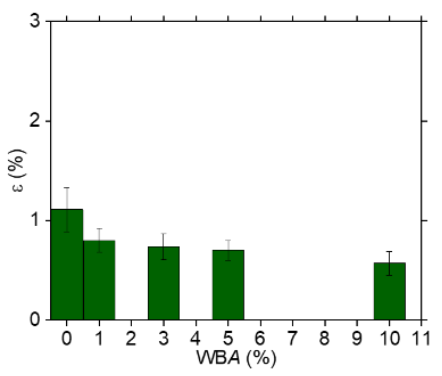

Fig. 5 A) Stress-strain curves of epoxy resin with different amount of WBA and B) flexural modulus, C) strength and D) deformation of composites as function of the content of WBA

It is well known that the modulus of a composite is dependent on the moduli and weight fraction of the composite constituents [4]. As we can see from Figures 3, 4, 5, the flexural modulus increases when increasing the ashes loading regardless of the particle size. However, the Epoxy_WBA10 composite shows a prominent increase in modulus. In detail, the Epoxy_MA samples are all characterized by a flexural modulus higher than that one of the epoxy matrix. The composites modulus increases when compared to the neat matrix of $7 \%, 27 \%, 66 \%$ and $86 \%$ for a MA content of $1 \mathrm{wt} \%, 3 \mathrm{wt} \%, 5 \mathrm{wt} \%$ and $10 \mathrm{wt} \%$, respectively. Unlike the modulus, the strength of each carbon ashes based epoxy composites behaves differently. In particular, the addition of the untreated filler (MA) causes a decrease of the strength as a function of the amount of the filler, from 34.1 MPa to 16.7 MPa for the neat epoxy and the composite containing $10 \mathrm{wt} \%$ of the filler, respectively. On the other hand, for the samples containing the ashes with reduced dimensions, the strength remains almost constant or, in some cases increases, as for example for the composites containing a DBA content of $3 \mathrm{wt} \%$ which increases by about $30 \%$. This result can be compared to the achievements obtained through the inclusion of the same concentrations of graphene nanoplatelets with an average size of $5 \mu \mathrm{m}$ in epoxy resin reported in $[4,6]$. A good dispersion of fillers in the epoxy matrix could contribute to higher modulus, while a weak interfacial adhesion between the fillers and epoxy resin could cause a decrease of flexural strength.

By increasing the amount of DBA above $1 \%$ a very limited improvement of properties was observed only for the strength. This can be associated to the poor dispersion obtained when the amount of DBA is increased. This counteracts the expected reinforcing effects.

The flexural modulus of the Epoxy_WBA samples increases compared to that of the matrix by up to 93\%. The flexural strength does not change significantly in comparison to that of the neat matrix.

In conclusion, DBA-filled epoxy composites and WBA-filled epoxy composites exhibit a clear improvement in flexural properties in comparison to the expanded graphite based nanocomposites, which are reported in the literature [6]. In detail, the flexural moduli of the Epoxy_DBA1 and Epoxy_WBA10 increase compared to that of the matrix of $104 \%$ and $93 \%$, respectively, while the modulus of epoxy nanocomposites containing an amount of expanded graphite of $3 \mathrm{wt} \%$ increases of $25 \%$, in comparison with that of the neat matrix [6]. The improvement of flexural modulus and strength could be attributed to the uniform distribution of the filler and its strong interfacial adhesion with the epoxy matrix. These latter results represent a very important achievement, since these mechanical performances were reached thanks to the presence of a carbon based waste filler, that, in this way can be re-used. 


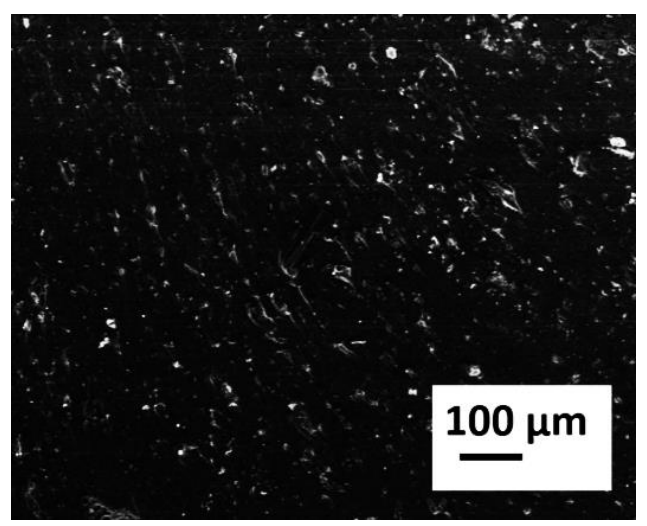

Fig. 6 SEM images of MA dispersion in Epoxy_MA10

The filler dispersion in the final composites was analysed by SEM. Fig. 6 shows the Epoxy_MA sample with the best flexural modulus. MA fillers appear to be homogeneously dispersed in the epoxy matrix and to have an average size of about $20 \mu \mathrm{m}$.

The glass transition temperature, $T_{g}$, of the cured epoxy composites was, finally, measured using a differential scanning calorimeter. Table 6 reports the values of $T_{\mathrm{g}}$ for each sample.

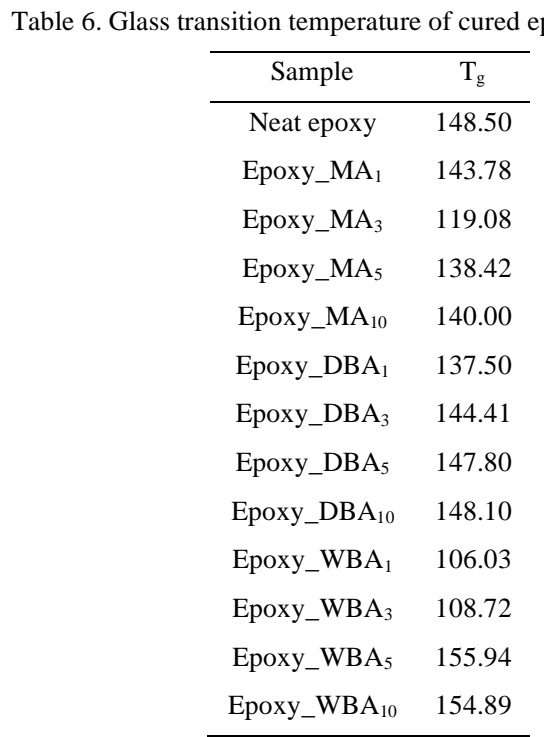

Only the epoxy composites containing $5 \mathrm{wt} \%$ and $10 \mathrm{wt} \%$ of WBA fillers revealed a slight increase in $\mathrm{T}_{\mathrm{g}}$. The $\mathrm{T}_{\mathrm{g}}$ of neat epoxy increased from $148^{\circ} \mathrm{C}$ to $155.94^{\circ} \mathrm{C}$ and $154.89^{\circ} \mathrm{C}$ at $5 \mathrm{wt} \%$ and $10 \mathrm{wt} \% \mathrm{WBA}$ loading, respectively. The increment in $\mathrm{T}_{\mathrm{g}}$ is attributed to the interactions between the carbon based fillers and the matrix, which restricts the segmental motion of cross-links under loading [9]. Many researchers $[9,10,11]$ also reported the increase of $\mathrm{T}_{\mathrm{g}}$ after the incorporation of graphite or GNP in different degrees depending on the filler dispersion, surface modification, degree of exfoliation, fraction and geometry.

\section{Conclusion}

This work focuses on the reinforcement of an epoxy resin by the addition of carbon-based wastes, derived from the pyro-gasification of innovative biomass and in the form of ashes fillers. The carbon-based fillers were systematically characterized in terms of morphological, structural and chemical properties. Steady rheological analyses evidence a slight increase of the viscosity of the liquid epoxy resin in presence of the fillers. Only in the case of $10 \mathrm{wt} \%$ of the filler with the largest size a non-Newtonian behaviour of the filled epoxy formulation was observed. 
Flexural tests were carried out on the cured epoxy composites produced with different quantities of fillers (ranging from $0 \mathrm{wt} \%$ to $10 \mathrm{wt} \%$ ). Results allowed for the choice of the mixture with the best mechanical properties. A comparison between results on epoxy with and without fillers showed that an increase in stiffness was attained with the addition of both fillers, produced by dry (DBA) and wet ball milling (WBA). The results obtained in this paper are encouraging compared to that achieved with GNP/epoxy nanocomposites, since here a waste carbon based filler is used. They aim to give out some ideas for the fabrication of low price high-performance composites. A high quality and cost-efficient method to reinforce the epoxy was obtained, by using a simple, economic, efficient and eco-friendly process method.

Acknowledgments: This project was funded by the National Operational Program for Research and Innovation 20142020 (CCI 2014IT16M2OP005) of the Ministry of Education, University and Research. The authors acknowledge with thanks the Ministry of Education, University and Research for the financial support.

\section{References}

[1] M. Costa, M. La Villetta, N. Massarotti, L. Vanoli, D. Cirillo, Proceedings of the 11th Conference on Sustainable Development of Energy, Water, and Environment Systems, SDEWES 0647 (2017) pp. 1-12.

[2] D. Cirillo, M. Costa, M. La Villetta, Z. Petranovic, D. Piazzullo, M. Vujanovic, Chem. Eng. Trans. 65 (2018).

[3] S. V. Vassilev, D. Baxter, L. K. Andersen, C. G. Vassileva, Fuel 105 (2013) pp. 19-39.

[4] F. Wang, L. T. Drzal, Y. Qin, Z. Huang, J. Mater. Sci. 50 (2015) pp. 1082-1093.

[5] L. C. Tang, Y. J. Wan, D. Yan, Y. B. Pei, L. Zhao, Y. B. Li, L. B. Wu, J. X. Jiang, G. Q. Lai, Carbon 60 (2013) pp. 16-27.

[6] C. Esposito Corcione, F. Freuli, A. Maffezzoli, Polym. Eng. and Sci. 53 (2013) pp 531-539.

[7] C. Esposito Corcione, A. Maffezzoli, Polym. Test. 32(5) (2013) pp. 880-888.

[8] Q. Wang, D. S. Su, Composites Communications 9 (2018) pp. 54-57.

[9] A. Yasmin, I. M. Daniel, Polymer 45 (2004) pp. 8211-8219.

[10] I. Zaman, B. Manshoor, A. Khalid, Q. Meng, S. Araby, J. Mater. Sci. 49 (2014) pp. 5856-5865.

[11] S. Jana, W. H. Zhong, J. Mater. Sci. 44(8) (2009) pp. 1987-1997. 